\title{
Trends in injury mortality among adolescents in Taiwan, 1965-94
}

\author{
Tsung-Hsueh Lu, Meng-Chih Lee, Ming-Chih Chou
}

\begin{abstract}
Objectives-To describe trends in injury mortality among adolescents in Taiwan for prioritising preventive interventions. Methods-Adolescent injury mortality data for Taiwan were derived from official publications of vital statistics from 1965 to 1994 to determine trends by sex and cause of death. Simple linear regression was used to test the trends.

Results-The number of deaths due to injury among adolescents aged 10-19 years in Taiwan increased from 983 in 1965 to 1783 in 1994 , an $81 \%$ increase. The injury mortality rate increased $42 \%$, from 32.2 per 100000 in 1965 to 45.6 per 100000 in 1994. The proportion of injury deaths also increased, from $45.3 \%$ in 1965 to $72.8 \%$ in 1994 . The trends in mortality from motor vehicle injury (MVI) among four demographic groups were all significantly positive $(p<0.001)$. The proportion of deaths due to MVI among injury was $14 \%$ in 1965 and increased to $63 \%$ in 1994. Conclusions-The increase in injury mortality rates among adolescents over the past three decades appears to be due largely to the increase in MVI mortality rates with males aged 15-19 years accounting for most of this increase. Priorities for adolescents in Taiwan are MVI (especially motorcyclists) and drownings. (Injury Prevention 1998;4:111-115)
\end{abstract}

Keywords: mortality trends; adolescence; Taiwan

Adolescents aged 10-19 years constitute one fifth of the total population in Taiwan. However, no health goals for this sizable demographic group were established until 1993. ${ }^{1}$ Most premature deaths among adolescents are preventable, such as motor vehicle injury (MVI), drowning, and other injuries. ${ }^{2-6}$ The proportion of deaths due to injury from 1992 to 1994 was $72 \%$ in Taiwan, ${ }^{7}$ which represents a tremendous unnecessary loss of life. International studies have revealed that the

(e-mail:

robertlu@ms1.hinet.net).

Table 1 ICD codes for adolescent injury mortality study in Taiwan, 1965-94

\begin{tabular}{llll}
\hline Cause of death & ICD-7 1965-70 & ICD-8 1971-80 & \multirow{2}{*}{ ICD-9 1981-94 } \\
\hline Total injury & E800-E999 & E800-E999 & E800-E999 \\
Unintentional injury & E800-E965 & E800-E949 & E800-E949 \\
Intentional injury & E970-E999 & E950-E999 & E950-E999 \\
Motor vehicle injuries & E810-E835 & E810-E823 & E810-E825 \\
Poisoning & E870-E895 & E985-E977 & E850-E869 \\
Falls & E900-E904 & E980-E987 & E880-E888 \\
Fires & E916 & E890-E899 & E890-E899 \\
Drowning & E929 & E910 & E910 \\
Suicide & E970-E979 & E950-E959 & E950-E959 \\
Homicide & E980-E985 & E960-E969 & E960-E969 \\
\hline
\end{tabular}

trends of adolescent injury mortality are decreasing mainly in industrialised countries. On the other hand, the mortality trends in some of the countries, especially developing countries, are increasing. ${ }^{8-12}$ In this study, we examine these trends from 1965 to 1994 among the adolescents in Taiwan, a newly industrialised country.

\section{Methods}

Mortality data were derived from official vital statistics for the period from 1965 to $1994 .{ }^{13} \mathrm{~A}$ five year period was chosen to provide more stable information. Adolescence was divided into early (10-14 years) and late (15-19 years). Causes of death were classified according to the International Classification of Diseases (ICD) 7th revision for the years 1965-70; ICD-8 for the years 1971-80; and ICD-9 for the years 1981-94. The term "injury" was used for all external causes (E code) as defined in the ICD. The codes we used for various specific injuries are listed in table 1. Simple linear regression was used to estimate the trend for each cause of death, separated by each age and sex group. The dependent variable in the regression equations was the mortality rate and the independent variable was the year.

\section{Results}

EXTERNAL $V$ NATURAL

The number of deaths due to injury (external causes of death) among adolescents aged 10-19 years in Taiwan increased from 983 in 1965 to 1783 in 1994 , an $81 \%$ increase. The mortality rate increased by $42 \%$, from 32.2 per 100000 in 1965 to 45.6 per 100000 in 1994 . The proportion of injury deaths also increased, from $45.3 \%$ in 1965 to $72.8 \%$ in 1994 . In contrast, the mortality rate from natural causes of death decreased, from 40.1 per 100000 in 1965 to 17.0 per 100000 in 1994 - a decrease of $58 \%$.

Tables 2 and 3 give the details of period specific mortality rates by age, sex, and cause of death. Among four demographic groups, only males aged 15-19 years showed a consistent and significant increase in mortality over the period $(p=0.008)$. In comparison, the slopes of mortality trends for natural causes of death among the four demographic groups were all significantly negative $(\mathrm{p}<0.001)$.

UNINTENTIONAL $V$ INTENTIONAL

As shown in table 2, the mortality trends among early adolescents for both unintentional injury (for example, MVI, poisoning, falls, drowning) and intentional injury (for example, 
Table 2 Injury mortality trends among early adolescents (10-14 years) in Taiwan from 1965-69 to 1990-94 per 100000

\begin{tabular}{|c|c|c|c|c|c|c|c|c|c|c|}
\hline \multirow[b]{2}{*}{ Cause of death } & \multirow[b]{2}{*}{ Sex } & \multicolumn{6}{|c|}{ Time period } & \multirow{2}{*}{$\begin{array}{l}\text { Total \% } \\
\text { change }\end{array}$} & \multirow[b]{2}{*}{$\beta$ Value } & \multirow[b]{2}{*}{ p Value } \\
\hline & & $1965-69$ & $1970-74$ & 1975-79 & $1980-84$ & $1985-89$ & 1990-94 & & & \\
\hline \multirow[t]{2}{*}{ Total } & M & 67.69 & 59.27 & 53.85 & 49.22 & 46.14 & 41.48 & -38.73 & -1.0004 & 0.0003 \\
\hline & $\mathrm{F}$ & 46.77 & 38.08 & 33.02 & 29.64 & 27.51 & 25.99 & -44.42 & -0.7942 & 0.0034 \\
\hline \multirow{2}{*}{ Natural } & M & 36.82 & 29.85 & 24.88 & 20.45 & 18.93 & 15.13 & -58.92 & -0.8322 & 0.0006 \\
\hline & $\mathrm{F}$ & 33.10 & 26.46 & 21.52 & 18.23 & 15.06 & 13.24 & -59.99 & -0.7817 & 0.0007 \\
\hline \multirow[t]{2}{*}{ Total injury } & M & 30.87 & 29.42 & 28.97 & 28.77 & 27.22 & 26.35 & -14.65 & -0.1680 & 0.0008 \\
\hline & $\mathrm{F}$ & 13.67 & 11.63 & 11.50 & 11.40 & 12.45 & 12.75 & -6.70 & -0.0128 & 0.7998 \\
\hline \multirow[t]{2}{*}{ Unintentional injury } & M & 28.56 & 28.27 & 28.26 & 27.88 & 26.28 & 25.28 & -11.49 & -0.1300 & 0.0104 \\
\hline & $\mathrm{F}$ & 11.32 & 9.80 & 10.38 & 10.46 & 11.81 & 12.15 & 7.34 & 0.0586 & 0.2093 \\
\hline \multirow{2}{*}{ MVI } & M & 4.52 & 4.86 & 5.88 & 7.57 & 8.77 & 11.28 & 149.67 & 0.2698 & 0.0011 \\
\hline & $\mathrm{F}$ & 2.91 & 2.89 & 3.97 & 4.64 & 5.26 & 6.97 & 139.71 & 0.1605 & 0.0017 \\
\hline \multirow{2}{*}{ Poisoning } & M & 0.62 & 0.50 & 0.57 & 0.50 & 0.71 & 0.33 & -46.76 & -0.0051 & 0.4727 \\
\hline & $\mathrm{F}$ & 0.65 & 0.71 & 0.46 & 0.61 & 0.66 & 0.58 & -11.67 & -0.0020 & 0.6809 \\
\hline \multirow[t]{2}{*}{ Falls } & $M$ & 1.03 & 0.95 & 1.06 & 1.28 & 0.71 & 0.66 & -35.66 & -0.0134 & 0.2672 \\
\hline & $\mathrm{F}$ & 0.36 & 0.27 & 0.48 & 0.57 & 0.51 & 0.31 & -14.23 & 0.0032 & 0.6344 \\
\hline \multirow[t]{2}{*}{ Fires } & M & 0.98 & 0.58 & 0.43 & 0.52 & 0.60 & 1.15 & 16.50 & 0.0057 & 0.7233 \\
\hline & $\mathrm{F}$ & 0.79 & 0.23 & 0.44 & 0.66 & 0.68 & 0.80 & 1.94 & 0.0093 & 0.4468 \\
\hline \multirow[t]{2}{*}{ Drowning } & M & 15.14 & 16.82 & 15.92 & 15.41 & 12.78 & 9.12 & -39.75 & -0.2442 & 0.0520 \\
\hline & $\mathrm{F}$ & 4.08 & 3.52 & 3.39 & 2.58 & 3.45 & 2.23 & -45.41 & -0.0587 & 0.0511 \\
\hline \multirow{2}{*}{ Intentional injury } & M & 2.31 & 1.15 & 0.71 & 0.89 & 0.93 & 1.07 & -53.74 & -0.0382 & 0.1890 \\
\hline & $\mathrm{F}$ & 2.35 & 1.82 & 1.12 & 0.94 & 0.64 & 0.60 & -74.49 & -0.0713 & 0.0032 \\
\hline \multirow{2}{*}{ Suicide } & M & 2.03 & 0.97 & 0.61 & 0.54 & 0.56 & 0.45 & -78.01 & -0.0526 & 0.0463 \\
\hline & $\mathrm{F}$ & 2.07 & 1.51 & 0.94 & 0.59 & 0.46 & 0.23 & -89.06 & -0.0726 & 0.0014 \\
\hline \multirow[t]{2}{*}{ Homicide } & M & 0.28 & 0.16 & 0.10 & 0.31 & 0.31 & 0.35 & 25.76 & 0.0057 & 0.2612 \\
\hline & $\mathrm{F}$ & 0.27 & 0.29 & 0.12 & 0.35 & 0.15 & 0.17 & -39.01 & -0.0039 & 0.4262 \\
\hline
\end{tabular}

suicide and homicide) were not significant. Table 3 shows that the trends for unintentional injury mortality among late adolescents were statistically significant and positive $(\mathrm{p}=0.006$ for males, $p=0.0001$ for females). Conversely, the trends for intentional injury mortality were negative $(p=0.037$ for males, $p=0.003$ for females).

MOTOR VEHICLE INJURY

The proportion of deaths due to MVI among all injuries was $14 \%$ in 1965 and increased to $63 \%$ in 1994. Table 2 and 3 show that the trends for MVI mortality among the four demographic groups were all significantly positive $(p<0.001)$. The mortality rates from MVI among late adolescents increased even more sharply - an increase of $512 \%$ for males and $541 \%$ for females between 1965-69 and 199094, respectively. Males aged 15-19 years showed a persistent increasing trend, with an annual increase of $2.3 \%$. From 1965-69 through 1990-94, the male/female MVI mortality ratio was around 1.5 among early adolescents and 3.5 to 4.5 among late adolescents. Figure 1 presents mortality rates from selected major causes of injury among adolescents from 1965-69 to 1990-94.

DROWNING

Drowning was the first leading cause of death among adolescents aged 10-19 years from 1965 to 1975 and then declined to second since 1976, where it has remained until the present. Nevertheless, drowning was the leading cause of death among the males aged 10-14 years from 1965 to 1990 . Both early and late adolescents did not show any significant decrease in drowning mortality rates during the study period (tables 2 and 3 ). On the average, about 350 adolescents died by drowning each year during the study period.

Table 3 Injury mortality trends among late adolescents (15-19 years) in Taiwan from 1965-69 to 1990-94 per 100 000

\begin{tabular}{|c|c|c|c|c|c|c|c|c|c|c|}
\hline \multirow[b]{2}{*}{ Cause of death } & \multirow[b]{2}{*}{ Sex } & \multicolumn{6}{|c|}{ Time period } & \multirow{2}{*}{$\begin{array}{l}\text { Total \% } \\
\text { change }\end{array}$} & \multirow[b]{2}{*}{$\beta$ Value } & \multirow[b]{2}{*}{$p$ Value } \\
\hline & & $1965-69$ & $1970-74$ & 1975-79 & $1980-84$ & $1985-89$ & $1990-94$ & & & \\
\hline \multirow[t]{2}{*}{ Total } & $M$ & 115.86 & 115.13 & 135.65 & 127.19 & 143.57 & 133.26 & 15.02 & 0.9363 & 0.0711 \\
\hline & $\mathrm{F}$ & 78.70 & 66.30 & 60.52 & 51.94 & 50.75 & 49.36 & -37.28 & -1.1562 & 0.0045 \\
\hline \multirow[t]{2}{*}{ Natural } & $\mathrm{M}$ & 49.04 & 42.73 & 38.16 & 31.00 & 26.68 & 24.10 & -50.85 & -1.0286 & 0.0001 \\
\hline & $\mathrm{F}$ & 42.39 & 36.52 & 30.34 & 22.41 & 20.40 & 18.48 & -56.40 & -1.0048 & 0.0009 \\
\hline \multirow[t]{2}{*}{ Total injury } & M & 66.83 & 72.40 & 97.49 & 96.20 & 116.89 & 109.16 & 63.35 & 1.9647 & 0.0081 \\
\hline & $\mathrm{F}$ & 36.31 & 29.78 & 30.17 & 29.53 & 30.35 & 30.88 & -14.96 & -0.1490 & 0.2642 \\
\hline \multirow[t]{2}{*}{ Unintentional injury } & M & 47.67 & 59.87 & 88.62 & 84.96 & 107.02 & 102.12 & 114.21 & 2.3431 & 0.0063 \\
\hline & $\mathrm{F}$ & 14.50 & 16.29 & 20.96 & 21.91 & 25.31 & 28.05 & 93.50 & 0.5472 & 0.0001 \\
\hline \multirow[t]{2}{*}{ MVI } & $M$ & 11.52 & 21.11 & 45.94 & 50.72 & 71.32 & 70.51 & 512.33 & 2.5735 & 0.0012 \\
\hline & $\mathrm{F}$ & 3.14 & 4.71 & 9.70 & 11.74 & 16.32 & 20.12 & 541.30 & 0.6958 & 0.0001 \\
\hline \multirow[t]{2}{*}{ Poisoning } & M & 3.11 & 2.93 & 2.75 & 2.43 & 3.04 & 2.46 & -20.91 & -0.0185 & 0.2135 \\
\hline & $\mathrm{F}$ & 2.80 & 3.23 & 3.50 & 2.54 & 2.24 & 1.99 & -28.89 & -0.0456 & 0.0940 \\
\hline \multirow[t]{2}{*}{ Falls } & $M$ & 1.20 & 2.41 & 2.33 & 2.57 & 2.46 & 2.69 & 124.19 & 0.0448 & 0.0716 \\
\hline & $\mathrm{F}$ & 0.68 & 0.59 & 0.73 & 0.89 & 0.94 & 0.97 & 43.41 & 0.0152 & 0.0099 \\
\hline \multirow[t]{2}{*}{ Fires } & M & 1.80 & 0.95 & 0.70 & 1.19 & 1.40 & 1.47 & -18.26 & 0.0011 & 0.9612 \\
\hline & $\mathrm{F}$ & 0.88 & 0.30 & 0.46 & 0.77 & 1.14 & 1.06 & 21.12 & 0.0213 & 0.2069 \\
\hline \multirow[t]{2}{*}{ Drowning } & M & 17.65 & 18.32 & 19.55 & 15.67 & 17.09 & 12.87 & -27.10 & -0.1798 & 0.1075 \\
\hline & $\mathrm{F}$ & 4.01 & 3.89 & 3.29 & 2.89 & 2.43 & 1.86 & -53.73 & -0.0887 & 0.0001 \\
\hline \multirow[t]{2}{*}{ Intentional injury } & $M$ & 19.16 & 12.53 & 8.87 & 11.24 & 9.86 & 7.04 & -63.22 & -0.3785 & 0.0373 \\
\hline & $\mathrm{F}$ & 21.82 & 13.49 & 9.21 & 7.62 & 5.04 & 2.83 & -87.03 & -0.6965 & 0.0034 \\
\hline \multirow[t]{2}{*}{ Suicide } & M & 16.62 & 9.91 & 5.94 & 6.73 & 5.84 & 3.83 & -76.97 & -0.4307 & 0.0221 \\
\hline & $\mathrm{F}$ & 20.91 & 12.86 & 8.86 & 7.32 & 4.21 & 1.72 & -91.75 & -0.7054 & 0.0021 \\
\hline \multirow[t]{2}{*}{ Homicide } & M & 2.54 & 2.56 & 2.69 & 4.15 & 3.81 & 2.33 & -8.02 & 0.0238 & 0.5764 \\
\hline & $\mathrm{F}$ & 0.90 & 0.59 & 0.29 & 0.25 & 0.81 & 0.77 & -14.44 & -0.0002 & 0.9913 \\
\hline
\end{tabular}



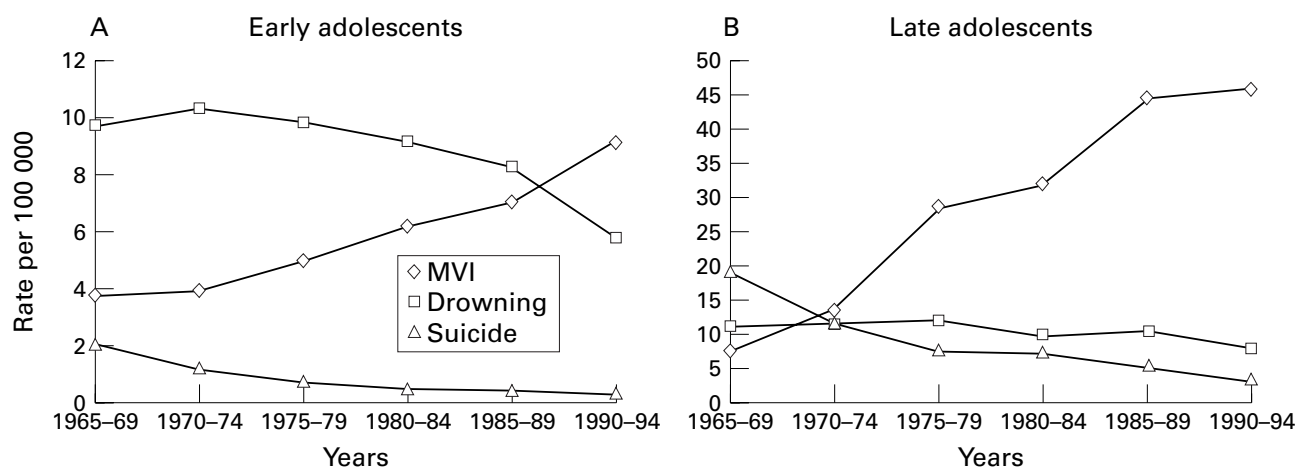

Figure 1 Mortality rates from selected major causes of injury among $(A)$ early adolescents (10-14 years) and (B) late adolescents (15-19 years) in Taiwan, 1965-69 to 1990-94. Source: Health Statistics II. Vital Statistics, 1965-94. ${ }^{13}$

SUICIDE AND OTHER INJURIES

Tables 2 and 3 reveal that both early and late female adolescents showed a highly significant decrease in suicide mortality $(p<0.005)$. However, analysis of the data for males did not reveal any significant trends. Figure 2 shows that the mortality rates from suicide among the female aged 15-19 were higher than those of males until 1984. After 1984, the male mortality rate from suicide exceeded the female rate. The death rates for other injuries showed no significant changes (tables 2 and 3 ).

\section{Discussion}

When interpreting mortality trends, we should bear in mind the effect of changes of reporting,

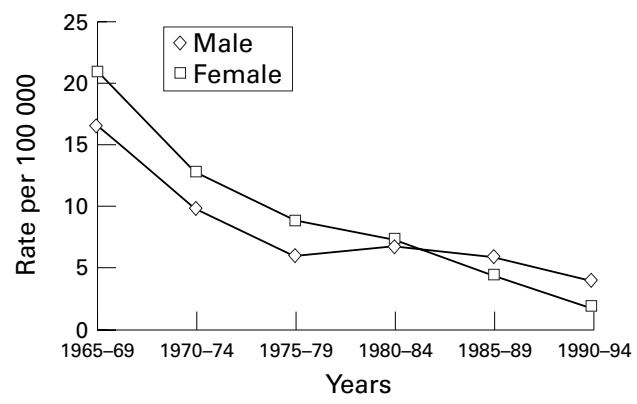

Figure 2 Mortality rates from suicide among late adolescents (15-19 years) by sex in Taizwan, 1965-69 to 1990-94. Source: Health Statistics II. Vital Statistics, $1965-94{ }^{1 .}$

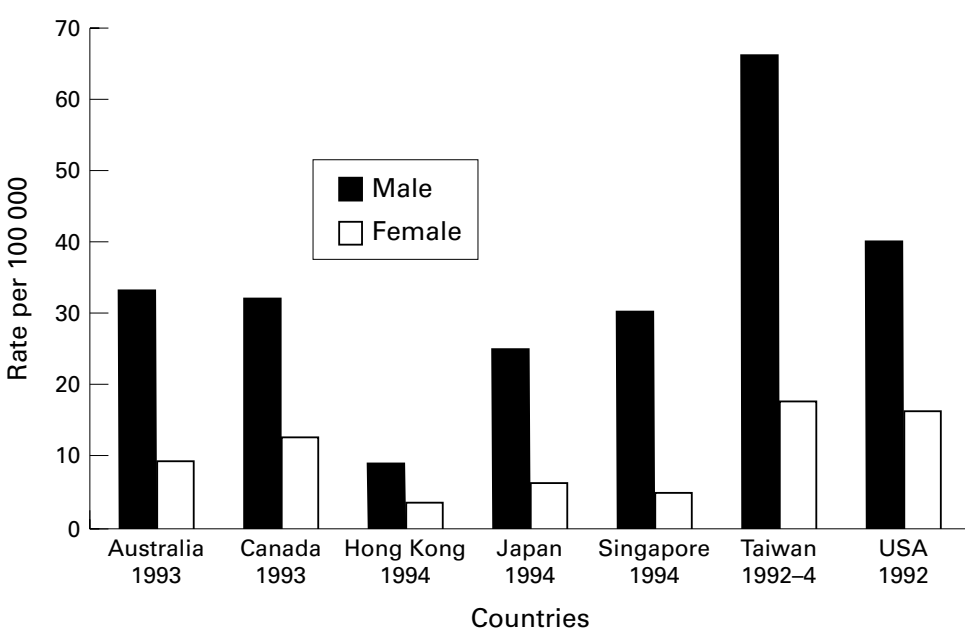

Figure 3 MVI mortality rates (15-24 years) for selected Asian and western countries. Source: World Health Statistics Annual, 1995. coding, and quality of cause of death diagnoses during the study period. The civil registration system in Taiwan is very complete in that every citizen has an ID number at birth. A death certificate can be issued only by a qualified doctor or coroner, and this certificate is required in order to repeal a citizen's civil registration. Therefore, the numerator and the denominator in the mortality rates are complete.

The Office of Health Statistics queries all death certificates when the causes of death were "signs, symptoms, and ill defined" for those aged 45 years old and less. ${ }^{14}$ The percentage of deaths in this category was only $3 \%$ among adolescents in Taiwan, in contrast to $10 \%$ in Israel and South Africa. ${ }^{15} 16$

The coding of injury did not change much from ICD-7 to ICD-9. A previous study has shown that the accuracy of injury related causes of death is better than that of other causes of death. ${ }^{17}$ Nevertheless, we still cannot rule out the possibility of misclassification or overlapping between unintentional and intentional causes. ${ }^{18}$

In this study, the increase in injury mortality rates among adolescents over the three decade study period appears to be due largely to an increase in MVI mortality rates. According to an international comparison study, the general pattern of mortality trends in MVI among adolescents for most countries was one of a rising mortality at first, followed by a levelling off, and then, in many cases, a decreasing rate. ${ }^{11}$ However, Taiwan has experienced an accelerating increase in MVI mortality among adolescents and the trend is continuing. Figure 3 shows the MVI mortality among adolescents and young adults aged 15-24 years in selected Asian and western countries. When compared with the selected countries, the male mortality rate in Taiwan was the highest. According to the mortality trends and the international comparison, we conclude that MVI has become epidemic among adolescents in Taiwan.

Many changes in traffic patterns have occurred during the last three decades that help explain the mortality trends in MVI. The most important of these is the effect of increasing motorisation. Figure 4 shows the strongly increasing trend in the number of motorcycles and passenger cars over this period. The increase in number of registered motorcycles per 1000 is similar to the increasing MVI 


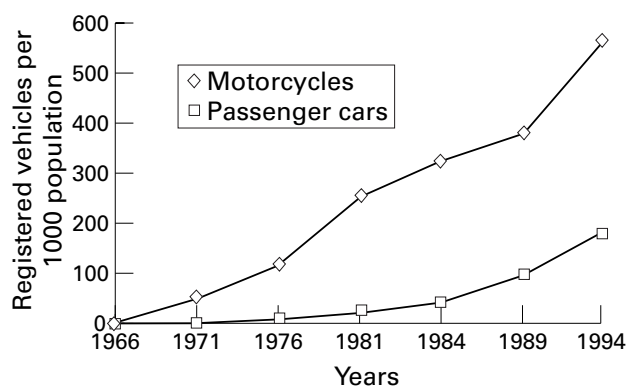

Figure 4 Registered vehicles in Taiwan, 1966 to 1994. Source: Statistical Abstract of Transportation and Communications, 1994 . $^{33}$

mortality rates. The motorcycle is the most common mode of transportation for short distances in Taiwan and the number of motorcycles has reached 11 million in a population of 22 million. Approximately $74 \%$ of all motor vehicles in Taiwan are motorcycles and motorcycle related deaths accounted for $48 \%$ of all motor vehicle injury deaths. ${ }^{19}$ An adolescent head injury study in Taiwan showed that $72 \%$ of the injuries were related to motorcycles. ${ }^{20}$

Yen and Li surveyed 1152 senior high school students (aged 14-19 years) in Hualien County, which has the highest MVI mortality rate in Taiwan, to determine the prevalence of hazardous motorcycling behaviour. ${ }^{21}$ For those who reported they had operated a motorcycle within the previous six months, $79 \%$ did so without a license, $64 \%$ said they drove at a high speed, $61 \%$ did not wear a helmet, and $15 \%$ drove after drinking. These hazardous behaviours may explain the increasing trend of MVI mortality among adolescents in Taiwan.

Although the mortality trends for drowning were not statistically significant, they are still the second leading cause of injury death among early and late adolescents. Swimming is, of course, most frequently associated with adolescent drowning ( $42 \%$ of cases)..$^{22}$ Eighty two per cent of these took place at unsupervised facilities or beaches - places not officially designated as "swimming areas". Taiwan is an oceanic island with a long coastline, thus the percentage of drowning due to swimming at unsupervised areas can be expected to be higher than in the US, for example.

If we assume that the bias for reporting suicide remained consistent during the study period, the epidemiological profiles of adolescent suicide mortality in Taiwan appear quite different than those in western countries. Most western countries experienced an increase of these suicide rates, ${ }^{23}$ whereas, during the same period the trends in Taiwan were decreasing. Although great efforts have been devoted principally through school and telephone counselling programs during the past decades in Taiwan to reduce the incidence of suicide, we believe that the misclassification of many suicides as MVI (using motorcycle as an agent for suicide) is the most plausible hypothesis to explain the unexpected downward trend.

Male adolescents usually have a higher suicide mortality rate than females in most countries, ${ }^{23}$ but the male/female mortality rate ratio among late adolescents in Taiwan did not exceed one until 1982. One possible explanation might be that Chinese culture favours males. Thus, as Wolf reports, family structure in Taiwan is more stressful for females. ${ }^{24}$ The suicide rate among Chinese females aged 15-24 was higher than among males. ${ }^{25}$ The slope of the decreasing trend among females is steeper than that of males in Taiwan, and this may be due to the liberalisation of constraints on gender roles and the increasing status of women during this time period.

\section{Implications for prevention}

In Taiwan, we use only three digit codes for cause of death statistics, and this limits our ability to compare our data with other countries $^{26-29}$ according to mechanism and intent of the injury, both of which are important in designing relevant prevention programs. According to this study, the priority of prevention among adolescents in Taiwan is MVI, with special attention to motorcyclists. The most effective preventive measures for motorcyclists are legislative and regulatory controls. ${ }^{30}$ Taiwan passed a mandatory helmet use law in March 1997 and this was enacted in July 1997. This suggests that there is some hope that the trend for MVI will level off and even decreasing in the near future. Zwi reminds us that considerable caution should be exercised in assuming the applicability and relevance of injury control policies in vastly different contexts. ${ }^{31}$ Passing of a law is not a guarantee of its enforcement. Taiwan already has a law for minimum legal driving age and licensing, but the data of Yen and Li show that there are still many senior high school students who ride motorcycles without a license. ${ }^{21}$ Injury control advocates in Taiwan should spend more time in auditing the enforcement of such laws.

1 Department of Health. Toward the goal of health for all-a health white paper. Taipei: Department of Health, Executive Yuan, 1993.

2 Runyan CW, Gerken EA. Epidemiology and prevention of adolescent injury - a review and research agenda. $7 A M A$ $1989 ; 262: 2273-9$

3 Centers for Disease Control and Prevention. Mortality trends and leading causes of death among adolescents and young adults-United States, 1979-1988. Morb Mortal young adults-United States, 1979-1

4 Runyan CW. Commentary: adolescent injury epidemiology and control. Adolescent Medicine State of the Art Review 1995;6:xi-xiii.

5 Singh GK, Yu SM. Trends and differentials in adolescent and young adult mortality in the United States, 1950 through 1993. Am F Public Health 1996;86:560-4.

6 Sells CW, Blum RW. Morbidity and mortality among US adolescents: an overview of data and trends. Am $\mathcal{F}$ Public Health 1996;86:513-19.

7 Lu TH, Lee MC, Chou MC. Injury mortality among youth in Taiwan: pattern of changes and international comparisons. f Formos Med Assoc (in press).

8 Maucusson H, Oehmisch W. Accident mortality in childMaucusson H, Oehmisch W. Accident mortality in child-
hood in selected countries of different continents, 1950hood in selected countries of different con

9 Havard JDJ. Mortality from motor vehicle accidents in the 15-24 year age group. World Health Stat $Q$ 1979;32:22541

10 Manciaux M, Romer CJ. Accidents in children, adolescents and young adults: a major public health problem. World Health Stat $Q$ 1986;39:227-31.

11 Taket A. Accident mortality in children, adolescents and young adults. World Health Stat $Q$ 1986;39:232-56.

12 Williams BC, Kotch JB. Excess injury mortality among children in the United States: comparison of recent interdren in the United States: comparison of recent in

13 Department of Health, Executive Yuan. Health statistics II. Vital statistics. Taiwan, ROC, 1965-1994. 
14 Taiwan Provincial Department of Health. Manual of cause-of-death statistics. Nantou: Taiwan Provincial Department of Health, 1994.

15 Wilf-Miron R, Gurvich R, Barell V. Cause-specific mortality among Israeli adolescents in the 1980s. $\mathscr{f}$ Adolesc Health 1994;15:186-91.

16 Flisher AJ, Joubert G, Yach D. Mortality from external causes in South African adolescents, 1984-1986. S Afr Med f 1992;81:77-80.

17 Moyer LA, Boyle CA, Polluck DA. Validity of death certificates for injury-related causes of death. Am $\mathcal{F}$ Epidemiol 1989;130:1024-32.

18 Peck DL, Warner K. Accident or suicide? Single-vehicle car accidents and the intent hypothesis. Adolescence 1995;30: 463-72.

19 Chiu WT. Motorcycle helmet law in Taiwan. $7 A M A$ 1995;274:941-2

20 Lin HW, Chiu WT, Kuo CY, et al. A descriptive epidemiological study of head injury among adolescents. Fournal of Taipei Medical College 1994;6:102-6 (in Chinese).

21 Yen LL, Li YM. Prevalence and correlates of hazardous motorcycling behavior among students in Hualien senior high school. Chin f Public Health (Taipei) 1997;16:396403.

22 Smith GS, Brenner RA. The changing risks of drowning for adolescents in the US and effective control strategies. Adolescent Medicine State of the Art Review 1995;6:153-69.

23 Jeanneret O. A tentative epidemiological approach to suicide prevention in adolescence. If Adolesc Health 1992;13 409-14.
24 Wolf $M$. Women and suicide in China. In: Wolf $M$, Witke R, eds. Women in Chinese society. Stanford, CA: Stanford Unieds. Women in Chinese society.
versity Press, 1975:111-14.

$25 \mathrm{Li} \mathrm{G}$, Baker SP. A comparison of injury death rates in China and the United States, 1986. Am f Public Health 1991;81:605-9.

26 Fingerhut LA, Annest JL, Baker SP, et al. Injury mortality among children and teenagers in the United States, 1993. Inj Prev 1996;2:92-4.

27 Scott I, Moller J, Bordeaux S. Injury mortality among children and teenagers in Australia, 1994. Inj Prev 1997;3:467.

28 DiGuiseppi C, Roberts I. Injury mortality among children and teenagers in England and Wales, 1992. Inj Prev 1997; 3:47-9

29 Langley JD, Smeijers J. Injury mortality among children and teenagers in New Zealand compared with the United States of America. Inj Prev 1997;3:195-9.

30 Munro J, Coleman P, Nicholl J, et al. Can we prevent accidental injury to adolescents? A systematic review of the evidence. Inj Prev 1995;1:249-55.

31 Zwi A. Injury control in developing countries: context more Zwi A. Injury control in developing countries:
than content is crucial. Inj Prev 1996;2:91-2.

32 World Health Organisation. World health statistics annual. Gorld Health Organis

33 Department of Statistics, Ministry of Transportation and Communications. Statistical abstract of tranportation and communications, 1994 Republic of China. Taipei: Ministry of Transportation and Communications, 1995.

It's amazing what happens to things inadvertently set on a car's roof

Dear Ann Landers: You printed a letter from a woman who said she had absentmindedly placed a set of keys on the roof of her car and forgotten all about them. After driving across the Oakland Bay Bridge and up and down the winding hills of San Francisco, she was amazed to discover that the keys were still there. Here is something that tops that story by a country mile.

A woman in Tinley Park, IL, placed her 2 month old son, who was in his car seat, on the roof of her car. The woman, who also had her 6 year old and 4 year old children in the car, had pulled over to pick up a friend and the friend's infant. In order to make room for the two new passengers, she temporarily placed her infant son on the roof of the car. She then took off, forgetting that the baby was there. The child, still strapped to the car seat, fell off the roof of the car into a busy intersection, with cars whizzing by in all directions.

Michael Prough, a trucker from Merrillville, IN, passed the intersection and spotted what he thought was a toy car seat on the highway. He might have continued on his way, but the baby blanket caught his eye, and he turned back to investigate. Prough and his coworker, Harold Eaton, discovered the baby and flagged down a passing police car. An ambulance was called, and the infant was taken to the hospital. The doctors said the car seat protected the child from serious injury.

The baby is in good condition, with just a few cuts and bruises, so one might say, "All's well that ends well”. I call it a miracle (St Louis (Missouri) Post-Dispatch, February 1998).

\section{The downside of summer}

Australia's long, hot summer is always anticipated eagerly. The disbenefit is the number of people, particularly adults, who drown at surf beaches. Most of the popular swimming beaches are patrolled by volunteer surf lifesavers and no-one has drowned at patrolled beaches. One poignant but preventable incident occurred at a beach south of Melbourne in January 1998 when four members of the same family drowned. A 4 year old girl and a 7 year old boy were being supervised by their teenage cousins after being caught in a rip off Gunnamatta beach. Both the children and the teenage supervisors were swept out to sea. The boy was rescued but died later. The parents who drove their offspring to the beach had mistaken the unpatrolled beach for a patrolled beach further away. There were apparently no warning signs. The incident prompted a series of television advertisements advising swimmers to swim only at patrolled beaches - but it was too little, too late. The advertising campaign should have started much earlier, before the public flocked to beaches nationwide during the summer holiday season. Undoubtedly the same scenario will be played out again later in the year, but will we remember the lessons of Gunnamatta? (Contributed by Jan Shield). 